\title{
A case of severe pneumonia caused by multiple bacterial organisms following type B influenza virus infection
}

\author{
Minako Sato, Eri Tomioka, Jouji Horio, Shotaro Chubachi, Tatsu Matsuzaki, \\ Takeshi Terashima* \\ Department of Respiratory Medicine, Tokyo Dental College Ichikawa General Hospital, Ichikawa, Japan; \\ *Corresponding Author: terasima@tdc.ac.jp
}

Received 9 December 2013; revised 30 December 2013; accepted 10 January 2014

Copyright (C) 2014 Minako Sato et al. This is an open access article distributed under the Creative Commons Attribution License, which permits unrestricted use, distribution, and reproduction in any medium, provided the original work is properly cited. In accordance of the Creative Commons Attribution License all Copyrights (C) 2014 are reserved for SCIRP and the owner of the intellectual property Minako Sato et al. All Copyright (C) 2014 are guarded by law and by SCIRP as a guardian.

\section{ABSTRACT}

A 50-year old woman, without any underlying disease, presented with pneumonia after experiencing flu-like symptoms. Streptococcus pneumoniae was identified on admission through blood culture and urine antigen tests. Staphylococcus aureus and Streptococcus pneumoniae were present in the sputum culture. Computed tomography showed cavity development in the consolidation areas, typical of staphylococcal pneumonia. The patient was intubated and received mechanical ventilation as respiratory failure progressed. She exhibited improvement following antibiotic therapy. The change in type $B$ influenza virus serum titer confirmed that this was a unique case of severe pneumonia caused by multiple bacterial organisms following type $B$ influenza virus infection.

\section{KEYWORDS}

Type B Influenza; Influenza Pneumonia; Streptococcus Pneumoniae; Staphylococcus Aureus; Severe Pneumonia

\section{INTRODUCTION}

Bacterial pneumonia has been reported to occur following influenza virus infection, and Streptococcus pneumoniae, Staphylococcus aureus, and Haemophilus influenzae are the most common pathogens in such cases [1-3]. Bacterial pneumonia may be lethal, particularly in infants and elderly patients [4-6]. The majority of the severe cases of bacterial infection are those that accom- pany type A influenza infection [7,8]. Moreover, influenza type B is generally considered to be less pathogenic than type A, and is believed to cause less morbidity and mortality in previously healthy adults [9]. Moreover, underlying diseases have been reported to be risk factors for influenza-related bacterial pneumonia [10-12]. In the present report, we describe a unique case of severe pneumonia caused by multiple bacterial organisms following type B influenza in a female with no underlying disease.

\section{CASE REPORT}

A 50-year old woman with no underlying disease was admitted to our hospital due to progressive fever and dyspnea. Eleven days prior to admission, she experienced fever and cough. Over the next 3 days, her condition spontaneously improved, and she was able to resume work. During that time, there was an outbreak of type B influenza infection in her family. Five days prior admission, the patient's body temperature increased to $>40 \mathrm{C}$. She developed an illness characterized by anorexia, general fatigue, pleuritic chest pain, and dyspnea. These symptoms became progressively worse and necessitated hospitalization.

At admission, a physical examination indicated that she was a well-developed, well-nourished woman. Her body temperature was $38.3^{\circ} \mathrm{C}$, blood pressure was $103 / 73$ $\mathrm{mmHg}$, pulse was 136 beats/min, respiratory rate was 30 breaths/min, and oxygen saturation was $91 \%$ on room air. A coarse crackle was heard throughout both the lungs. None of the other results of the physical examination were remarkable. Examination of a nasopharyngeal swab sample using a rapid test kit (Protest Flu A; Mitsubishi Medience, Tokyo Japan) did not indicate the presence of 
either type A or B influenza virus antigen. An initial laboratory examination showed a white blood cell count of $7800 / \mu \mathrm{L}$ with $95 \%$ neutrophils, C-reactive protein level of $36.3 \mathrm{mg} / \mathrm{dL}$, blood urea nitrogen (BUN) level of 84.4 $\mathrm{mg} / \mathrm{dL}$, and creatinine level of $4.2 \mathrm{mg} / \mathrm{dL}$. Blood gas analysis under administration of $\mathrm{O}_{2}(2 \mathrm{~L} / \mathrm{min})$ indicated a $\mathrm{pH}$ of 7.43, $\mathrm{PaCO}_{2}$ of $19.2 \mathrm{mmHg}, \mathrm{PaO}_{2}$ of $68.8 \mathrm{mmHg}$, and $\mathrm{HCO}_{3}^{-}$of $12.7 \mathrm{mmol} / \mathrm{L}$. Stained smears of sputum revealed gram-positive cocci and gram-negative rods. Chest radiography (Figure 1) and computed tomography (CT) (Figures 2(a) and (b)) showed multiple consolidation areas, indicating the presence of lobar pneumonia. Infection by Streptococcus pneumoniae was confirmed on blood culture and a urine antigen test at admission.

The patient was treated with ceftriaxone ( $4 \mathrm{~g} / \mathrm{day})$. On the 4th day, we noted that the Streptococcus pneumoniae obtained from blood culture indicated sensitivity to 0.06 $\mu \mathrm{g} / \mathrm{mL}$ of ampicillin (ABPC). Therefore, the antibiotic regimen was changed to ABPC (8 g/day). Staphylococcus aureus with $\beta$-lactamase and Haemophilus haemolyticus, as well as Streptococcus pneumoniae were detected on culture of sputum collected at admission. On the 9th day, CT indicated cavity formation in the consolidation areas (Figures 3(a) and (b)), which was identified as a typical feature of staphylococci pneumonia. The antibiotic regimen was then changed to sulbactam/ABPC (9 g/day). During the first 2 weeks of hospitalization, the patient's physical condition and laboratory findings improved gradually. However, on the 18th day, the patient developed respiratory failure. Blood gas analysis under administration of $\mathrm{O}_{2}(15 \mathrm{~L} / \mathrm{min})$ via a face mask with

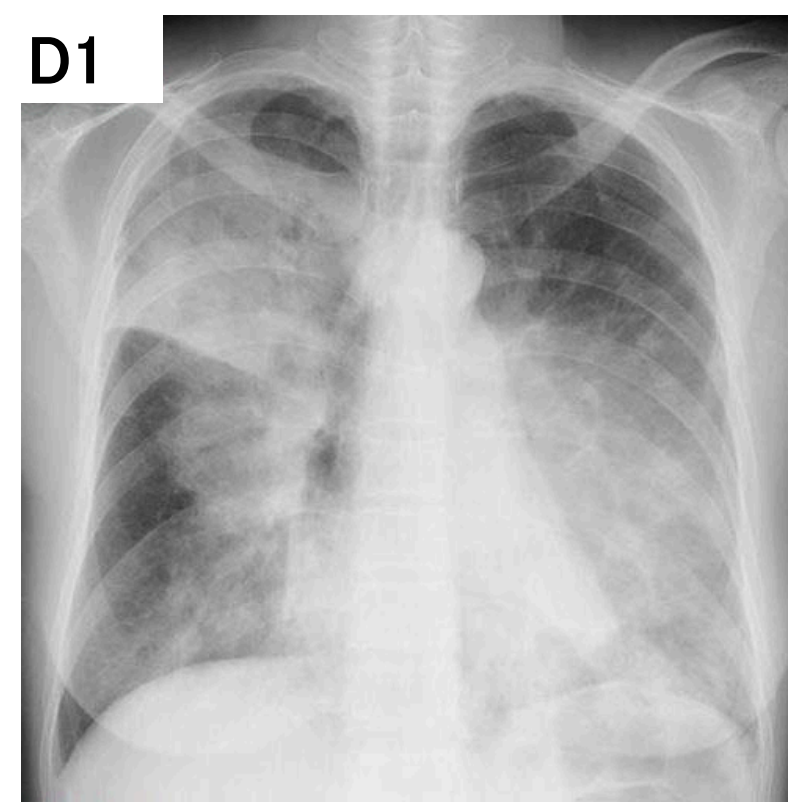

Figure 1. Chest radiography image on admission, showing multiple infiltrates in the right upper lobe, right lower lobe, and left lower lobe.
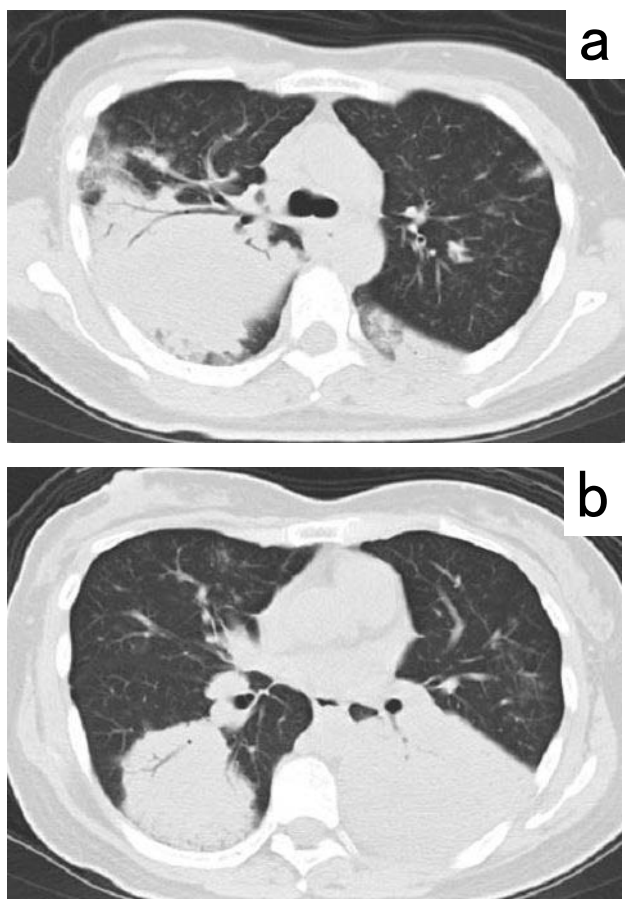

Figure 2. Chest computed tomography image on admission, showing multiple consolidation areas with an air bronchogram in the right upper lobe (a), and the bilateral lower lobes (b), indicating the presence of lobar pneumonia.

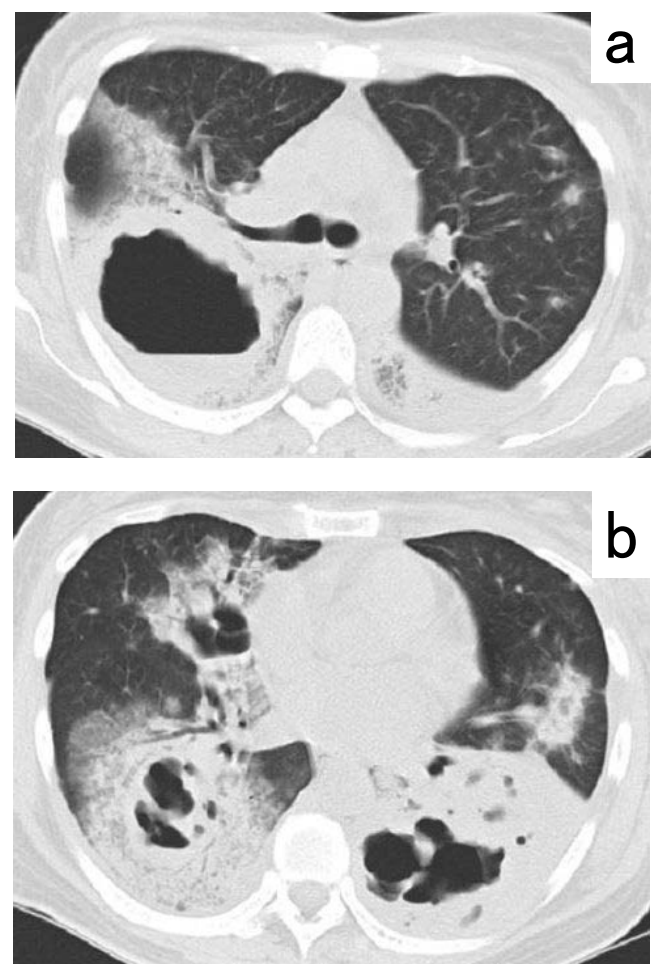

Figure 3. Chest computed tomography on the 9th day, showing multiple consolidation areas with a cavity in the right upper lobe (a); right middle lobe, and both lower lobes (b). 
reservoir indicated $\mathrm{pH}$ of $7.49, \mathrm{PaCO}_{2}$ of $36.7 \mathrm{mmHg}$, $\mathrm{PaO}_{2}$ of $57.6 \mathrm{mmHg}$, and $\mathrm{HCO}_{3}^{-}$of $27.6 \mathrm{mmol} / \mathrm{L}$. The patient was intubated and received mechanical ventilation in the intensive care unit. The initial $\mathrm{PaO}_{2} / \mathrm{FIO}_{2}$ ratio was $71 \mathrm{mmHg}$. The findings of chest radiography were not suggestive of acute respiratory distress syndrome or heart failure. A combination therapy of meropenem (2 g/day), ciprofloxacin (600 mg/day), and teicoplanin (400 mg/day) was administered. In addition, Pseudomonas aeruginosa was detected on culture of respiratory samples on the 18th day. Gradual improvement was observed, and the patient was extubated on the 32nd day. She was discharged and is currently being followed at an outpatient clinic. Examination showed no evidence of underlying diseases or immunodeficiency. In addition, the serum levels of complement fixation antibody against type B influenza virus were 1:512 on admission, 1:256 on the 18th day, 1:32 on the 51st day, and 1:16 on the 136th day. The serum titer of type A influenza virus was not found to be increased at admission or throughout the clinical course.

\section{DISCUSSION}

In the present report, we describe a unique case of severe pneumonia following type $B$ influenza virus infection in a previously healthy woman. The patient showed an increased respiratory rate and elevated BUN levels on admission with a CURB score of 2 [13]. She developed respiratory failure and received mechanical ventilation. These features were suggestive of severe pneumonia [14, 15]. Type B influenza has been classically considered to be less pathogenic than type A influenza in adults and infection with type B most often causes only mild symptoms. The present report is particularly notable, as we describe a case where type $B$ influenza infection resulted in a serious clinical course.

Staphylococcus aureus, Streptococcus pneumoniae, and Haemophilus influenzae have been reported to be the major causative organisms for bacterial pneumonia following influenza virus infection [1-3]. Initially, we believed that the organism responsible for pneumonia in our patient was Streptococcus pneumoniae alone, on the basis of the results of both the blood culture and urine antigen test. Although cavity formation may be noted in pneumococcal pneumonia [16], it has generally been regarded as a rare complication and has been observed in only $6.6 \%$ of adults [17]. However, cavity formation was observed in 7 (27\%) of 26 patients with staphylococcal pneumonia in one study [18] and 5 (16\%) of 31 in another study [19]. In the present case, based on the radiographic finding of multiple cavity formation and the bacterial results of the culture of sputum collected at admission, the involvement of Staphylococcus aureus was also suspected in the development of pneumonia. To our knowledge, there are only a few reported cases of bacterial pneumonia caused by multiple organisms from onset, following influenza infection without any underlying disease. A previous report showed that among 15 patients with bacterial pneumonia who were affected by influenza virus co-infection, only a single bacterial strain was isolated, and none of the patients indicated infection by multiple organisms [20]. Furthermore, it was previously shown that among 15 patients with bacterial pneumonia following influenza infection, both Staphylococcus aureus and Streptococcus pneumoniae were cultured from one patient with underlying heart disease, and both Staphylococcus aureus and Haemophilus influenzae were cultured from another patient [1]. According to a review by Joseph et al., Staphylococcus aureus, Streptococcus pneumoniae, and Haemophilus influenzae were the main bacterial pathogens associated with severe infection or death in the pandemics of the 20th century [21]. One potential cause of the severe pneumonia in the present case may be that both Staphylococcus aureus and Streptococcus pneumoniae contributed to the disease. Alternatively, it may be possible that a subsequent infection with Pseudomonas aeruginosa may worsen the clinical course. In a previous study of 15 patients with bacterial pneumonia following influenza virus infection, only 1 patient showed consolidation of 3 lobes [1]. Thus, we believe that the present case, involving consolidation in 3 lobes, is unique in terms of its rarity and severity.

Our patient was serologically established as having been infected with type B influenza. It was previously reported that an initial complement fixing antibody titer of 1:128 of greater against influenza represents clear evidence of infection [1]. The titer in the present case was sufficiently high to indicate the presence of type $B$ influenza virus infection, which was subsequently confirmed by the change in the serum titer.

There was a brief period of improvement after influenza infection, followed by the development of new symptoms comprising pleural pain and dyspnea, which indicated the presence of bacterial pneumonia infection. This definite period of improvement was similar to the period between influenza infection and secondary pneumonia reported in a previous study [1]. The antiviral drug, oseltamivir, administered within 48 hours of symptom onset has been known to improve survival in patients with severe influenza, and may reduce secondary bacterial infection [21]. The patient in our study was not treated with antivirals because 11 days had passed between the onset of flu-like symptoms and treatment.

Type B influenza is generally regarded as having a lower morbidity and mortality in healthy persons, compared to type A influenza. The mortality rates of community-acquired pneumonia associated with types $\mathrm{A}$ and type $\mathrm{B}$ influenza have been reported to be $9.0 \%$ and $0 \%$, respectively [7]. A description of 850 cases in Korea 
during the seasonal outbreak of influenza in 2011-2012 included 656 cases of type A and 194 of type B. Of these cases, there were 68 hospitalizations and 2 fatal cases attributed to type A influenza and 11 hospitalizations and no fatal cases attributed to type B influenza [22]. Some studies have reported that type B influenza primarily affects the elderly and individuals with underlying diseases $[9,15]$.

Case reports have recently been published on severe streptoccocal infection associated with type B influenza in previously healthy adults in South East England [23] and Switzerland [24]. Awareness of the role that type B influenza infection may play in the severity of influenza-related illness is growing [21]. Based on previous literature and the information presented in this case, it is important to consider the possibility of multiple contributing organisms, particularly Staphylococcus aureus and Streptococcus pneumoniae, to bacterial pneumonia following type B influenza infection, and the potential for rapid progression to severe pulmonary failure.

\section{REFERENCES}

[1] Louria, D.B., Blumenfeld, H.L, Ellis, J.T., Kilbourne, E.D. and Rogers, D.E. (1959) Studies of the pandemic of 1957-1958. II. Pulmonary complications of influenza. Journal of Clinical Investigation, 38, 213-265. http://dx.doi.org/10.1172/JCI103791

[2] Brundage, J.F. (2006) Interactions between influenza and bacterial respiratory pathogens: Implications for pandemic preparedness. Lancet Infectious Diseases, 6, 303-312. http://dx.doi.org/10.1016/S1473-3099(06)70466-2

[3] Morens, D.M., Taubenberger, J.K. and Fauci, A.S. (2008) Predominant role of bacterial pneumonia as a cause of death in pandemic influenza: Implications for pandemic influenza preparedness. The Journal of Infectious Diseases, 198, 962-970. http://dx.doi.org/10.1086/591708

[4] Metersky, M.L., Masterton, R.G., Lode, H., File, T.M. and Babinchak, T. (2012) Epidemiology, microbiology and treatment considerations for bacterial pneumonia complicating influenza. International Journal of Infectious Diseases, 16, e321-e331. http://dx.doi.org/10.1016/j.ijid.2012.01.003

[5] Glezen, W.P. (1982) Serious morbidity and mortality associated with influenza epidemics. Epidemiologic Reviews, 4, 25-44.

[6] Serfung, R.E., Sherman, I.L. and Houseworth, W.J. (1967) Excess pneumonia-influenza mortality by age and sex in three major influenza A2 epidemics, United States, 195758, 1960 and 1963. American Journal of Epidemiology, 86, 433-441.

[7] Fine, M.J., Smith, M.A., Carson, C.A., et al. (1996) Prognosis and outcomes of patients with community-acquired pneumonia. A meta-analysis. JAMA, 274, 134-141. http://dx.doi.org/10.1001/jama.1996.03530260048030

[8] Scheiblauer, H., Reinacher, M., Tashiro, M. and Rott, R. (1992) Interactions between bacteria and influenza A vi- rus in the development of influenza pneumonia. The Journal of Infectious Diseases, 166, 783-791.

http://dx.doi.org/10.1093/infdis/166.4.783

[9] Thompson, W.W., Shay, D.K., Weintraub, E., et al. (2004) Influenza-associated hospitalizations in the United States. Journal of the American Medical Informatics Association, 292, 1333-1340. http://dx.doi.org/10.1001/jama.292.11.1333

[10] Bisno, A.L., Griffin, J.P., Van Epps, K.A., Niell, H.B. and Rytel, M.W. (1971) Pneumonia and Hong Kong influenza: A prospective study of the 1968-1969 epidemic. The American Journal of the Medical Sciences, 261, 251-263. http://dx.doi.org/10.1097/00000441-197105000-00004

[11] Nichol, K.L., Wuorenma, J. and Von Sternberg, T. (1998) Benefits of influenza vaccination for low-, intermediateand high-risk senior citizens. Archives of Internal Medicine, 158, 1769-1776.

http://dx.doi.org/10.1001/archinte.158.16.1769

[12] Lindsay Jr., M.I., Herrmann Jr., E.C., Morrow Jr., G.W. and Brown Jr., A.L. (1970) Hong Kong influenza: Clinical, microbiologic and pathologic features in 127 cases. Journal of the American Medical Informatics Association, 214, 1825-1832. http://dx.doi.org/10.1001/jama.1970.03180100019004

[13] Lim, W.S., Van Der Eerden, M.M., Laing, R., et al. (2003) Defining community acquired pneumonia severity on presentation to hospital: An international derivation and validation study. Thorax, 58, 377-382. http://dx.doi.org/10.1136/thorax.58.5.377

[14] Mandell, L.A., Wunderink, R.G., Anzueto A., et al. (2007) Infectious diseases society of America/American thoracic society consensus guidelines on the management of community-acquired pneumonia in adults. Clinical Infectious Diseases, 44, S27-S72. http://dx.doi.org/10.1086/511159

[15] Gutiérrez-Pizarraya, A., Pérez-Romero, P., Alvarez, R., et al. (2012) Unexpected severity of cases of influenza B infection in patients that required hospitalization during the first postpandemic wave. Journal of Infection, 65, 423430. http://dx.doi.org/10.1016/j.jinf.2012.07.004

[16] Leatherman, J.W., Iber, C. and Davies, S.F. (1984) Cavitation in bacteremic pneumococcal pneumonia. Causal role of mixed infection with anaerobic bacteria. American Review of Respiratory Disease, 129, 317-321.

[17] Pande, A., Nasir, S., Rueda, A.M., et al. (2012) The incidence of necrotizing changes in adults with pneumococcal pneumonia. Clinical Infectious Diseases, 54, 10-16. http://dx.doi.org/10.1093/cid/cir749

[18] Macfarlane, J. and Rose, D. (1996) Radiographic features of staphylococcal pneumonia in adults and children. Thorax, 51, 539-540. http://dx.doi.org/10.1136/thx.51.5.539

[19] Kaye, M.G., Fox, M.J., Bartlett, J.G., Braman, S.S. and Glassroth, J. (1990) The clinical spectrum of staphylococcus aureus pulmonary infection. Chest, 97, 788-792. http://dx.doi.org/10.1378/chest.97.4.788

[20] Seki, M., Kosai, K., Yanagihara, K., et al. (2007) Disease severity in patients with simultaneous influenza and bacterial pneumonia. Internal Medicine, 46, 953-958. http://dx.doi.org/10.2169/internalmedicine.46.6364 
[21] Joseph, C., Togawa, Y. and Shindo N. (2013) Bacterial and viral infections associated with influenza. Influenza and Other Respiratory Viruses, 7, 105-113. http://dx.doi.org/10.1111/irv.12089

[22] Wie, S., So, B.H., Song, J.Y., et al. (2013) A comparison of the clinical and epidemiological characteristics of adult patients with laboratory-confirmed influenza A or B during the 2011-2012 influenza season in Korea: A multi-center study. PLoS One, 8, Article ID: e62685. http://dx.doi.org/10.1371/journal.pone.0062685
[23] Scaber, J., Saeed, S., Ihekweazu, C., Efstratiou, A., McCarthy, N. and O’Moore, E. (2011) Group a streptococcal infections during the seasonal influenza outbreak 2010/11 in South East England. Eurosurveillance, 16, pii:19780.

[24] Aebi, T., Weisser, M., Bucher, E., Hirsch, H.H., Marsch, S. and Siegemund, M. (2010) Co-infection of influenza B and streptococci causing severe pneumonia and septic shock in healthy women. BMC Infectious Diseases, 10, 308. http://dx.doi.org/10.1186/1471-2334-10-308 